\title{
COחE)-(OES
}

CIÊNCIA E TECNOLOGIA

\section{POSSIBILIDADES TEÓRICO-PRÁTICAS DA AVALIAÇÃO CURRICULAR PARA A EDUCAÇÃO PROFISSIONAL}

\author{
Patrícia Helena Carvalho Holanda ${ }^{1}$, Meirecele Caliope Leitinho ${ }^{2}$ \\ ${ }^{1}$ Universidade Federal do Ceará - UFC, Programa de Pós - Graduação em Educação \\ ${ }^{2}$ Universidade Federal do Ceará - UFC, Universidade Estadual do Ceará - UECE \\ <profa.patriciaholanda@gmail.com>, <meirecele@ terra.com.br> \\ DOI: <https://doi.org/10.21439/conexoes.v14i5.1784>
}

\begin{abstract}
Resumo. O texto apresenta o trabalho desenvolvido pelo eixo de Pesquisa Avaliação Curricular, vinculado à Linha de Pesquisa Avaliação Educacional do Programa de Pós-Graduação em Educação Brasileira da Universidade Federal do Ceará (PPGE/UFC), no período de 2007 a 2013. O referido eixo foi criado com o objetivo de não só formar pesquisadores na área de avaliação curricular, mas, também, de contribuir para a ampliação da teoria na área com base empírica. Para tanto, desenvolveu duas ações de forma integrada: a oferta de uma disciplina chamada Avaliação Curricular e um projeto de pesquisa intitulado Experiências de Avaliação Curricular: possibilidades teórico-práticas. Essas duas ações agregaram professores, orientadores, orientandos do eixo e docentes e técnicos do Instituto Federal de Educação Ciência e Tecnologia do Ceará (IFCE), favorecendo a produção científica do período. Como contribuições importantes do eixo supracitado, identificamos uma ampliação do campo teórico-metodológico com base empírica e a formação de avaliadores pesquisadores.
\end{abstract}

Palavras-chaves: Avaliação Curricular. Referenciais teórico-metodológicos. Formação de Avaliadores.

\section{THEORETICAL-PRACTICAL POSSIBILITIES OF CURRICULAR ASSESSMENT FOR PROFESSIONAL EDUCATION}

\begin{abstract}
The text presents the work developed by the Curriculum Evaluation Research axis, linked to the Educational Evaluation Research Line of the Graduate Program in Brazilian Education of the Federal University of Ceará (PPGE / UFC), from 2007 to 2013. The referred axis It was created with the objective of not only training researchers in the area of curriculum evaluation, but also contributing to the expansion of the theory in the area with empirical basis. To this end, it developed two actions in an integrated way: the offer of a discipline called Curriculum Evaluation and a research project entitled Curriculum Evaluation Experiences: theoretical and practical possibilities. These two actions brought together teachers, advisors, students of the axis and teachers and technicians of the Federal Institute of Education Science and Technology of Ceará (IFCE), favoring the scientific production of the period. As important contributions of the aforementioned axis, we identified an expansion of the empirically based theoretical-methodological field and the formation of research evaluators.
\end{abstract}

Keywords: Curriculum Evaluation. Theoretical-methodological References. Training of Evaluators.

\section{INTRODUÇÃO}

O presente artigo é fruto do trabalho desenvolvido junto ao eixo de pesquisa Avaliação Curricular, vinculado à Linha de Pesquisa Avaliação Educacional, do Programa de Pós-Graduação em Educação em Educação Brasileira da Universidade Federal do Ceará (PPGE/UFC), no período de 2007 a 2013. O estudo em questão foi apresentado na mesa-redonda Internacionalização, Instituições Educativas, Avaliação, Currículo e Educação Superior! no evento promovido pelo

\footnotetext{
${ }^{1}$ Evento promovido pelo IFCE, I Ciclo Internacional de Palestras sobre Educação Superior na América do Sul: perspectivas para o
}

Instituto Federal de Educação Ciência e Tecnologia do Ceará (IFCE), instituição que integra a Rede Federal de Educação Profissional, Científica e Tecnológic:2. Vale destacar a atualidade da temática do evento face aos novos desafios impostos para as instituições de ensino superior nos últimos tempos, tais como as diferenças regionais, a pressão pelo aumento de vagas, os custos elevados, a necessidade de expansão, a autonomia didáticoadministrativa, dentre outras. Fornece-nos uma ideia

\footnotetext{
século XXI.

${ }^{2}$ IFCE: criado em 29 de dezembro de 2008, pela Lei $\mathrm{N}^{\circ}$ $11.892 / 2008$
} 
para entendermos as dificuldades a serem superadas no futuro próximo.

O trabalho realizado no PPGE/UFC evidenciou a proficuidade de criar um eixo de pesquisa com a finalidade de capacitar pesquisadores na área de avaliação curricular e contribuir para a ampliação da sua teorização com base empírica da área. Em parte, fomos motivadas pela preocupação de estudiosos como Avanzini apud (ESTRELA; NóVOA, 1993), dentre outros, ao destacarem que a avaliação curricular é uma área que se constituiu como prática antes de se desenvolver como teoria, configurando-se como área da Ciência da Educação.

Destarte, partimos da convicção de que a formação docente deverá ocorrer através da integração entre docência e pesquisa, visto se tratar de um fenômeno extremamente dinâmico, o qual se organiza e se operacionaliza de forma processual, através da soma contínua de experiências significantes.

Inspiradas em tais ideias, planejamos o trabalho do eixo de pesquisa Avaliação Curricular de modo a articular teoria e prática em duas frentes: a oferta de uma disciplina, a qual denominamos de Avaliação Curricular; e um projeto de pesquisa intitulado Experiências de Avaliação Curricular: possibilidades teóricopráticas 3 , que agregou professores, orientadores e orientandos do eixo, favorecendo a produção científica do período. configurou-se como uma pesquisa "guardachuva" organizada a partir de princípios da pesquisa colaborativa e da participante, com a pretensão de contribuir para responder a seguinte questão: Quais percursos avaliativos são mais adequados à área de avaliação curricular?

No tocante à disciplina, adotamos em sua organização uma metodologia que contemplasse grupos de discussão e estudos investigativos de natureza avaliativa, desenvolvidos pelos alunos mestrandos e doutorandos do referido eixo de pesquisa, orientados pelos seus professores. Na culminância do trabalho da disciplina, com o intuito de articular ensino e pesquisa, além de divulgar os referidos projetos, elaboramos um livro intitulado Experiências de Avaliação Curricular: possibilidades teórico-práticas (HOLANDA; LEITINHO, 2011). A publicação ocorreu em coautoria com os alunos da disciplina supracitada em 2011.

Desse modo, desenvolver pesquisa de forma colaborativa consiste na busca de soluções coletivas, através da escuta e da partilha de práticas e percepções, uma vez que, para se concretizarem, é necessário a coprodução de saberes e experiências, segundo Ibiapina (2008). Já a

\footnotetext{
${ }^{3}$ Projeto de Pesquisa registrado no Conselho Nacional de Desenvolvimento Científico e Tecnológico (CNPq).
}

pesquisa participante produz conhecimento e possibilita cooperação e laboração em grupo. Para Demo (2000), a pesquisa participante é qualitativa, cientificamente fundamentada e que expressa uma ideologia, tendo como um de seus objetivos propiciar a participação da população na pesquisa e a intervenção na realidade. Pois, na relação teoria e prática, esta exerce um destaque na relação sujeito-objeto, contribuindo para a constituição de uma identidade totalizante.

\section{O TRABALHO DESENVOLVIDO NO EIXO DE PESQUISA AVALIAÇÃO CURRICULAR}

Para responder aos objetivos propostos pela pesquisa, de estudar/compreender quais percursos avaliativos são mais adequados à área de avaliação curricular, inspiramo-nos em Anastasiou (2006), ao defender que, “[...] na função do ensino da universidade, é importante considerar a relação existente entre a organização curricular, construída historicamente, e a visão de conhecimento dominante naquele momento histórico" (p. 42).

Os referenciais teóricos que orientaram os estudos e investigações do eixo Avaliação Curricular são decorrentes das teorias do currículo (tradicional, crítica e póscrítica). Esses referenciais supramencionados se integram à avaliação curricular de forma multirreeferencial, possibilitando a associação da concepção de currículo como uma política cultural produzida socialmente, gerando significados e relações de poder, bem como uma concepção de avaliação, denominada democrática e emancipatória, não mais centrada na busca de fatos e conhecimentos objetivos, mas, nos fenômenos oriundos do objeto de avaliação, fundamentada em princípios fenomenológicos e no pensamento discursivo de natureza crítica.

Silva (2000) define o currículo como "[...] discurso, documento e identidade [...]" e reafirma que se trata de um "[...] documento de identidade" (p.155). O autor elege como ponto fulcral da sua teoria curricular o porquê. Assim, as teorias curriculares tradicionais se encontram mais inclinadas para as questões técnicas, de organização, enfatizando "o quê?", nunca estando desvinculada de uma outra indagação igualmente importante: "O que é que eles devem ser?" ou, melhor, "Em que eles devem se tornar?". Entretanto, nas teorias do currículo, a indagação "O que?" se encontra vinculada a uma outra pergunta, também importante: "Por que essa forma de ensinar e não outra?". Silva (2000), ao buscar a explicitação dos porquês, coloca em cena reflexões sobre os conhecimentos e sua validade, e como estes e a avaliação podem repercutir na vida das pessoas.

A opção por autores como Silva (1999), Apple 
(1993), Giroux Henry A. E Mclaren (1993), para realizar a avaliação, encontra-se associada à tendência dos currículos atuais se configurarem em função dos seus atores sociais e das teorias que lhe fundamentam em um determinado tempo histórico. Pois, nos dias atuais, quando pensamos na educação superior e, particularmente, no currículo, somos instados a pensar em pesquisa e problemáticas com um olhar interdisciplinar, de inovação tecnológica e comparada, com o ponto de convergência na articulação entre os planos local e global, isto é, indo do particular ao universal, à proporção que se geram intercâmbios e circulação de ideias no círculo acadêmico.

Tal situação pode ser observada numa Conferência das Nações Unidas sobre mudança climática, momento em que uma jovem questiona os delegados com a seguinte indagação: Que idade vocês terão em 2050? Em outras palavras, ela queria dizer que "[...] o tipo de mundo em que ela um dia vai viver depende daqueles que o herdarem e daqueles que o deixam como legado" 4 Assim, na perspectiva do currículo, surge a seguinte indagação: Que tipo de pessoas queremos formar em 2050? E para fazer o quê em 2050?

Isso nos leva a pensar que a jovem na referida Conferência do Fundo das Nações Unidas para a Infância (UNICEF) representa a sua geração nos questionando sobre qual o nosso posicionamento diante da negligência em relação à preservação do ambiente, em que assistimos aos perigos que vêm ocorrendo com a mudança climática, cujas consequências são mais visíveis nos países em desenvolvimento, os quais já apresentam implicações no bem-estar de crianças e adolescentes. Acrescente-se, ainda, a nossa problematização que, de acordo com o relatório da UNICEF 20175 apesar de nos últimos tempos ter ocorrido uma redução da mortalidade infantil, com milhões de crianças passando a frequentarem a escola, 28 crianças e adolescentes são assassinados por dia no Brasil. Como lidar com a gravidez precoce? O que fazer diante de dados tão alarmantes? De vidas cerceadas antes mesmo de florescerem numa etapa que deveria ser de oportunidade de crescimento? E como pensar uma formação para os jovens que não conseguem um posto de trabalho?

As problemáticas apresentadas nos colocam diante do desafio de redimensionar os nossos conceitos de educação, pois, o conhecimento não pode ficar restrito apenas a uma dimensão pedagógica, uma vez que extrapola a esfera existencial e política. Nesse sentido, possibili-

\footnotetext{
${ }^{4}$ Situação Mundial da Infância 2011. Disponível em: $\quad<$ https://www.ebah.com.br/content/ABAAABpMoAI/ unicef-situacao-mundial-infancia-2011.> Acesso em: mar./2019.

${ }^{5}$ Disponível em: < <https://www.unicef.org/brazil/pt/UNI_39. pdf>.> Acesso em: mar./2019.
}

tar aos jovens oportunidades de vivenciarem boa educação, saúde, habitação e melhoria das suas comunidades é um investimento na melhoria da nossa sociedade. $\mathrm{Na}$ verdade, ao considerar a Teoria Crítica de Giroux (1983, 1997), podemos perceber que os processos educacionais são demasiadamente perpassados pelos fenômenos sociais, históricos e políticos, os quais constituem o processo de formação do indivíduo, isto é, a sua dimensão psicológica. Por via de consequência, possui implicações pessoais e éticas, em virtude de defender o argumento de que a sociedade deve adotar mecanismos mais humanos para atender aos interesses dos homens, ou seja, numa perspectiva que oportunize a libertação do homem e de sua sociedade.

Outro aspecto relevante consiste em compreender que o currículo não pode se limitar a áreas de conhecimento restrito, daí a necessidade da interdisciplinaridade ser contemplada no Projeto Curricular. Sobre esse aspecto, Vigotski (1994) nos adverte para resistirmos à tentação de realizar uma superposição de disciplinas por ocasião da elaboração de Projetos Curriculares, ao afirmar que "[...] o aprendizado é mais que a capacidade de pensar, é a aquisição de muitas capacidades especializadas para pensar sobre várias coisas" (p. 108). Isso se deve ao fato de o autor defender que o conhecimento é uma produção cultural que inclui os acontecimentos ditos científicos ou lógicos matemáticos, mas não fica restrito aos mesmos. Por esse motivo, restringir o ensino a áreas específicas diminui não só a amplitude do conhecimento, mas, também, as possibilidades de realização da avaliação, uma vez que as práticas de ensino se encontram intrinsecamente relacionadas com as práticas avaliativas.

Daí a proficuidade de estudo da teoria de Vigotsk $\sqrt{6}$ para a avaliação curricular, por possibilitar o acesso a subsídios para a identificação da influência de aspectos culturais no processo de ensino-aprendizagem dos alunos e, por via de consequência, da avaliação de sua aprendizagem, devido ao fato da teoria está voltada para a gênese dos processos psicológicos característicos dos humanos em seus contextos histórico-culturais. Por conseguinte, os estudos na linha de avaliação curricular permitem que se possa ter uma visão mais crítica dos sistemas de ensino e da sala de aula. A avaliação é um mecanismo propiciador da melhoria contínua do ensino-aprendizagem, cumprindo, assim, a sua função de diagnosticar, reforçar e permitir ao aluno crescer, já que o processo pedagógico deve ser uma de suas finalidades.

(COOL, 1987) traz sua contribuição para a discus-

\footnotetext{
${ }^{6}$ Lev Semenovich Vigostski (1896-1934), fundador da Escola Histórico-Cultural.
} 
são ao defender que a avaliação do Projeto Curricular deve partir da indagação: Avaliar, para quêe? Ou, em outros termos, "Que funções a avaliação deve desempenhar?". Para autor, a avaliação deve permitir atuações que possibilitem ajustar o Projeto Curricular às características e necessidades dos alunos, investigando até que ponto foram atendidas ou não as metas propostas, no sentido de evidenciar em que grau as intenções do Projeto Pedagógico foram atingidas. Para ele, o currículo precisa ser "[...] um elo entre a declaração de princípios gerais e sua tradução operacional, entre a teoria educacional e a prática pedagógica, entre o planejamento e a ação, entre prescrito e o que realmente sucede nas salas de aulas" (COOL, 1987, p. 33-34).

Para atingir o objetivo proposto no projeto, no que diz respeito ao currículo, foram estudadas, também, as ideias de Apple (1993) que abordam a educação de forma relacional: classe e cultura na sociologia do conhecimento escolar; as ideias de Giroux (1987), inspiradas na Escola de Frankfurt, dentre elas a "Teoria crítica e resistência em educação". Giroux superou as posições neomarxistas da teoria da reprodução de Althusser, Bourdieu e Passeron, dentre outros. Inspirou-se nas ideias de Gramsci e, numa elaboração sintética de todas essas posições, cria o conceito de resistência. Na obra supracitada, o autor, ao falar sobre o papel dos professores radicais, conclama os professores a lutarem para tornar possível a democracia escolar. Analisa a escola como um local de dominação e reprodução, mas que, ao mesmo tempo, propicia às classes oprimidas um espaço de resistência.

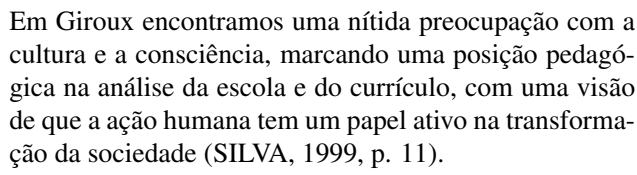

Pacheco (2005), por sua vez, defende o currículo como uma construção social, cultural, individual e ideológica, fundamentando-se no pensamento de Gimeno ao afirmar que o documento se organiza a partir de uma “[...] seleção cultural estruturada sob condições psicopedagógicas dessa cultura que se oferece como projeto para a instituição escolar" (p. 61).

Entre os autores nacionais, além de Silva, foi estudado, também, Moreira e Candau (2008), dentre outros. Esses estudiosos compreendem o currículo como um artefato social e cultural, o qual se encontra implicado em relações de poder, possuindo uma história e se localiza ligado a formas específicas e contingentes de organização da sociedade e da educação.

Os currículos instituídos, os quais foram objeto de estudo dos nossos alunos durante a disciplina, apresentam ideologias que precisam ser explicitadas, discutindo-se as práticas pedagógicas originárias da teoria de legitimação vigente no momento histórico da sua formulação. Mediante a consciência de tais aspectos, é possível se apropriar de uma teoria que seja capaz de formar um currículo de natureza crítica e emancipatória, fundado em práticas democráticas.

Os estudos geraram uma produção científica (artigos na forma de capítulos de livros organizados e publicados pelos professores, pesquisadores e alunos do eixo supracitado). Vale destacar que, esses estudos ampliaram os referenciais epistemológicos das Dissertações de Mestrado, Teses de Doutorado e Relatórios de Estágios Científicos de Pós-Doutorado.

\section{ATIVIDADES DESENVOLVIDAS NO EIXO}

As atividades desenvolvidas no âmbito do eixo de pesquisa supramencionado foram divulgadas em eventos científicos realizados em Instituições de Ensino Superior (IES) locais, regionais e internacionais, a ver:

- Realização de pesquisas exploratórias, vinculadas aos projetos de dissertação e tese - Trabalho Final da Disciplina Avaliação Curricular;

- Organização de eventos para socialização dos estudos e pesquisas do eixo no Fórum Mundial de Educação Profissional e Tecnológica em Brasília, no IFCE, na Faculdade de Educação (FACED) da $\mathrm{UFC}$;

- Palestras proferidas pelos professores pesquisadores do grupo de pesquisa em avaliação curricular em eventos locais, regionais e nacionais;

- Elaboração de Relatório de Estágio Científico de Pós-Doutorado dos professores do eixo na Universidade de Brasília (UNB);

- Grupo de estudos, com reuniões semanais, contando com a presença de especialistas em avaliação da UFC, UNB, Universidade Estadual do Ceará (UECE), Secretaria da Educação do Estado do Cerará (SEDUC) e Escola de Saúde Pública do Ceará (ESP), dentre outras instituições, para realizarem discussões reflexivas;

- Realização de três seminários de avaliação curricular, sendo o último realizado no encerramento das atividades, com a apresentação das teses e dissertações defendidas no eixo. 
POSSIBILIDADES TEÓRICO-PRÁTICAS DA AVALIAÇÃO CURRICULAR PARA A EDUCAÇÃO PROFISSIONAL

\section{PRODUÇÃO CIENTÍFICA DO EIXO AVALIA- ÇÃO CURRICULAR}

A produção científica realizada no desenvolvimento da disciplina e da pesquisa resultou na publicação do livro intitulado Experiências de Avaliação Curricular: possibilidades teórico-práticas (HOLANDA; LEITINHO, 2011). A obra é composta por 10 capítulos produzidos pelos alunos a partir do exercício de práticas avaliativas realizadas no âmbito dos projetos exploratórios vinculados aos seus projetos de dissertação e tese, apresentando para o debate questões teóricometodológicas.

Acrescente-se, ainda, à produção do eixo de pesquisa, a publicação de um segundo livro, A Avaliação Curricular Iluminando os Caminhos da Educação Profissional (HOLANDA; LEITINHO; CUNHA, 2013), elaborado como um trabalho de escrita colaborativa. A obra contém estudos decorrentes de pesquisas avaliativas sobre os currículos de Educação Profissional realizadas em diferentes instituições do Norte, Nordeste e Sudeste do Brasil. Os estudos foram elaborados a partir de Dissertações de Mestrado, Teses Universidade de Doutorado, em desenvolvimento ou concluídas, e dos resultados das investigações realizadas no âmbito do Estágio Científico Pós-doutoral dos pesquisadores vinculados ao Grupo de Pesquisa Avaliação Curricular registrado no Conselho Nacional de Desenvolvimento Científico e Tecnológico (CNPq).

No período de 2007 a 2013, os integrantes do eixo de pesquisa Avaliação Curricular produziram 52 trabalhos científicos que foram divulgados em anais de eventos, periódicos e capítulos de livros, além das defesas de cinco Dissertações de Mestrado, seis Teses de Doutorado e a produção de dois Relatórios Científicos de Pós-Doutorado, os quais foram realizados na Universidade de Brasília, durante 12 meses.

Em relação às metodologias de investigação, as pesquisas enfatizaram o estudo de caso, as técnicas de análise documental, entrevista e observação participante. São procedimentos que foram utilizados na coleta de evidências empíricas, possibilitando uma ampla triangulação dos dados.

\section{CONTRIBUIÇÕES DO EIXO PARA O DE- SENVOLVIMENTO DE UMA TEORIZAÇÃO DA AVALIAÇÃO CURRICULAR COM BASE EMPÍRICA}

Durante o desenvolvimento da disciplina e do projeto de pesquisa foi possível, no decurso do processo dessas duas ações, observar, interpretar e testar metodologias de avaliação curricular, utilizando o diálogo e a confrontação dos resultados das experiências, exercitando uma abordagem colaborativa. Destarte, as contribuições identificadas no eixo para a avaliação curricular são:

1. produção de conhecimentos científicos sobre a teoria e a prática da avaliação curricular, no sentido de contribuir para que ela se torne uma área da Ciência da Educação. Tal ação favoreceu a autonomia face aos modelos e técnicas oriundos da avaliação educacional, colaborando para um estatuto epistemológico próprio da área;

2. demonstração da importância da avaliação de processo (formativa) ser articulada com a avaliação em larga escala como política educacional;

3. responder à questão orientadora da pesquisa "guarda-chuva" do eixo sobre as metodologias mais adequadas para a área de avaliação curricular, com ênfase no processo. A abordagem de pesquisa qualitativa foi predominante, embora tenha tido experiências quanti-qualitativa. No que diz respeito às metodologias mais adequadas às pesquisas na área de avaliação curricular, foram identificadas: estudo de caso, discurso do sujeito coletivo e pesquisa participante. Em relação às técnicas, têm-se: entrevista reflexiva, análise documental, observação participante e levantamento estruturado;

4. por último, destacamos a formação do avaliador pesquisador à medida que se primou pelo conhecimento técnico-científico como resultado de um trabalho de articulação de ensino-pesquisa.

Concordamos com o pensamento de Veiga-Neto et al. (2002) sobre os caminhos investigativos na atualidade, quando destaca que "[...] não há um porto seguro onde possamos ancorar nossas perspectivas de análise para a partir de ali conhecer a realidade" (p. 33). Isso significa que devemos ter múltiplos olhares teóricometodológicos, desvelando os fenômenos nos seus contextos. À vista disso, prosseguimos concordando com o pensamento do autor ao externar o seu objetivo no artigo intitulado Olhares, nos seguintes termos:

\footnotetext{
[...] dou-me por satisfeito se puder contribuir para que cada professor e cada professora não aceite automática e silenciosamente, de modo não problemático, as declarações que vêm há mais de duzentos anos dando sustentação ao mundo moderno, e, de certa maneira, contribuindo para justificar o autoritarismo e a dominação étinica, religiosa, racial, de gênero, etc- em termos ecnômicos, culturais, morais, politicos, etc (p.33).
} 
POSSIBILIDADES TEÓRICO-PRÁTICAS DA AVALIAÇÃO CURRICULAR PARA A EDUCAÇÃO PROFISSIONAL

\begin{tabular}{|c|c|}
\hline Nome do Autor(a) & Título da Dissertação de Mestrado \\
\hline Roseany Carla Dantas de Menezes & $\begin{array}{c}\text { A Prática Pedagógica na Perspectiva Curricular do Ensino Médio Integrado: } \\
\text { um estudo avaliativo. } 2012\end{array}$ \\
\hline Ana Cláudia Uchoa Araújo & $\begin{array}{l}\text { Avaliação do Currículo Integrado no PROEJA do IFCE: } \\
\text { concepções e prática na percepção do docente. } 2010\end{array}$ \\
\hline Ana Lourdes Lucena de Sousa & $\begin{array}{l}\text { Percepção da Escola-Campo sobre o Estágio Supervisionado em Biologia: } \\
\text { Contribuições para uma avaliação curricular. } 2009 .\end{array}$ \\
\hline $\begin{array}{l}\text { Elenita Maria Dias de Sousa } \\
\text { Aguiar }\end{array}$ & $\begin{array}{c}\text { Concepções e práticas de professores em avaliação da aprendizagem da } \\
\text { rede pública municipal de Teresina. } 2009 .\end{array}$ \\
\hline Cláudia Regina Furlanetto & $\begin{array}{c}\text { Avaliação de Aprendizagem na } 1^{\mathrm{a}} \text { série em uma escola Municipal de } \\
\text { Fortaleza: teoria e prática. } 2007 .\end{array}$ \\
\hline
\end{tabular}

\begin{tabular}{|c|c|}
\hline Nome do Autor(a) & Título da Dissertação de Mestrado \\
\hline Francisco Emílio Campelo Freitas & $\begin{array}{c}\text { Avaliando a Formação do Engenheiro no Centro de Tecnologia da } \\
\text { Universidade Federal do Ceará. 2012. }\end{array}$ \\
\hline Geison Vasconcelos Lima & $\begin{array}{c}\text { Epistemologia, Metodologia e Práxis de um Modelo Cartográfico de } \\
\text { Avaliação Curricular em Educação Médica. 2010 }\end{array}$ \\
\hline Ondina Maria Chagas Canuto & Avaliando Currículos dos Cursos Técnicos na Área da Saúde. 2011. \\
\hline Rita de Cássia Moura Diniz. & $\begin{array}{c}\text { Avaliação da Trajetória curricular dos cursos de Formação para Servidores } \\
\text { de Saúde do Sistema penitenciário do Estado do Ceará. 2011. }\end{array}$ \\
\hline Xênia Diógenes Benfatti & $\begin{array}{c}\text { A Avaliação do Currículo Integrado no Ensino Médio } \\
\text { com a Educação Profissional. 2011. }\end{array}$ \\
\hline Maria Lindalva Gomes Leal & $\begin{array}{c}\text { Concepções e Práticas de Avaliação Ensino-Aprendizagem: } \\
\text { Foco no Proeja do IFCE. 2014. }\end{array}$ \\
\hline João Eudes Moreira da Silva & $\begin{array}{c}\text { Estudo de Caso Avaliativo do Currículo Integrado do } \\
\text { Curso de Refrigeração e Climatização do PROEJA do IFCE. 2013. }\end{array}$ \\
\hline
\end{tabular}

O objetivo proposto por Veiga-Neto et al. (2002) nos chama a atenção para a importância da desnaturalização do olhar sobre a educação, particularmente, sobre as reformas que vêm sendo propostas nos últimos tempos. Do ponto de vista da avaliação curricular, faz sentido analisar os mecanismos presentes nos documentos de reformulação do ensino com o intuito de desvendar no texto o não-dito. Destarte, é possível compreender propostas que apresentam conteúdos que nos parecem naturais à primeira vista, mas, que, na prática, não operam com essa tal naturalidade. Guardando as devidas proporções, podemos apresentar alguma das explicações do fato de que o ensino superior e a educação profissional têm enfrentado as mesmas vicissitudes que os outros níveis do ensino e, nos últimos tempos, vêm atravessando uma de suas maiores crises. Por conseguinte, não está isento de lidar com rituais e atitudes discriminatórias.

\section{CONSIDERAÇÕES FINAIS}

Os referenciais teórico-metodológicos abordados na disciplina e nos projetos de pesquisa do eixo de avaliação curricular permitiram uma análise aprofundada de fundamentos e metodologias desenvolvidas nesse eixo. $\mathrm{O}$ estudo desses referenciais nos oportunizou perceber que as definições sobre a avaliação curricular se constroem pouco a pouco, tomando emprestado os elementos conceituais da avaliação educacional. Nesse sentido, teorias e práticas de avaliação curricular ainda são consideradas "emergentes", ou seja, elementos de um processo em construção.

Percebemos que a educação profissional, a partir da avaliação curricular, concedeu-nos um espaço de reflexão de modo a envolver a vida social, a estrutura curricular, a cultura institucional, as relações de trabalho, a vida social e as demais conexões necessárias ao entendimento das contradições e possibilidades de interações. Sem esquecer que o Programa Nacional de Integração da Educação Profissional com a Educação Básica na Modalidade de Educação de Jovens e Adultos (PROEJA) se caracteriza como um:

\footnotetext{
[...] projeto educacional que tem como fundamento a integração entre trabalho, ciência, técnica, tecnologia, humanismo e cultura geral com a finalidade de contribuir para o enriquecimento científico, cultural, político e profissional como condições necessárias para o efetivo exercício da cidadania (BRASIL 2007).
}

Por outro lado, não podemos esquecer que a modernidade traz um saber funcional, às vezes bem distante de um saber pessoal. A "máquina dinamiza", movi- 
POSSIBILIDADES TEÓRICO-PRÁTICAS DA AVALIAÇÃO CURRICULAR PARA A EDUCAÇÃO PROFISSIONAL

menta e substitui o homem. O processo produtivo remete para as instituições de ensino o papel de formar indivíduos flexíveis que dominem um código científico cada vez mais especializado, para o fazer entender o mundo que os cerca, criando um distanciamento entre conceptores e executores. Na maioria das vezes, atende às aspirações do liberalismo econômico, que tanto tem contribuído para a precarização do trabalho, os salários reduzidos e o fim dos direitos sociais.

Diante disso, precisamos unir forças para que a educação, nessa sociedade tecnológica, propicie a compreensão dos novos tempos, os valores dos novos universos descobertos, respeitando a cultura do seu povo, trabalhando com o conhecido e com o novo. As instituições de ensino superior, por sua vez, terão que desenvolver uma proposta pedagógica desafiadora, instigando o aluno de forma crítica, fazendo a mediação entre o tempo, os usuários e a tecnologia.

Acredito que a Educação deve ser concebida hoje como meio e fim, fim e meio, mas, também, pode ser vista como articuladora nas relações sociais e profissionais. E a avaliação, em meio aos novos tempos tecnológicos, surge como um importante instrumento para se repensar os processos de ensino-aprendizagem.

Outro aspecto que não podemos deixar de destacar foi o esforço dos integrantes do eixo Avaliação Curricular em realizar uma construção coletiva, de forma a criar um diálogo educativo e emancipatório, levando em conta: ideias, necessidades, limites, possibilidades, diferentes realidades e interlocuções do local com o nacional e o internacional. Sem esquecer da importância de considerar as forças convergentes e divergentes presentes nos processos avaliativos, nas dimensões políticopedagógicas, cultural e social. Em síntese, foi uma experiência valiosa na área de avaliação curricular, contribuindo, sobremaneira, para a tomada de decisões de gestores responsáveis por questões curriculares.

\section{REFERÊNCIAS}

ANASTASIOU, L. d. G. C. Processos de ensinagem na universidade: Pressupostos para as estratégias de trabalho em aula. In: ANASTASIOU, L. d. G. C.; ALVES, L. P. (Ed.). Da visão de ciência a organização curricular. 6 . ed. Joinville: UNIVILLE, 2006.

APPLE, M. Ideologia e Currículo. 1. ed. São Paulo: Brasiliense, 1993.

ARROYO, M. G. Indagações sobre currículo: educandos e educadores: seus direitos e o currículo. 1. ed. Brasília: Ministério da Educação, Secretaria de Educação Básica, 2008. v. 172.
BRASIL. PROEJA: Programa Nacional de Integração da Educação Profissional com a Educação Básica na Modalidade de Educação de Jovens e Adultos: Educação Profissional Técnica De Nível Médio / Ensino Médio: Documento Base. 1. ed. Brasilia, 2007.

COOL, C. Psicologia e currículo: uma aproximação psicopedagógica à elaboração do currículo escolar. 2. ed. São Paulo: Ática, 1987. Tradução de Claudia Schilling.

DEMO, P. Pesquisa Participante: saber pensar e intervir juntas. 2. ed. Brasília: Liber Livro, 2000.

ESTRELA, A.; NóVOA, A. Avaliação em Educação: novas perspectivas. 1. ed. Porto, Portugal: Porto Editora, 1993.

GIROUX, H. A. Escola Crítica e Política Cultural. 1. ed. São Paulo: Autores Associados, 1987.

GIROUX HENRY A. E MCLAREN, P. Linguagem, Escola e Subjetividade: elementos para um discurso pedagógico crítico. 18. ed. Porto Alegre: Educação E Realidade, 1993.

HOLANDA, P. H. C.; LEITINHO, M. C. Experiências de Avaliação Curricular: possibilidades teórico-práticas. 1. ed. Fortaleza: Edições UFC, 2011.

HOLANDA, P. H. C.; LEITINHO, M. C.; CUNHA, G. M. Avaliação Curricular Iluminando os Caminhos da Educação Profissional. 1. ed. Fortaleza: Edições UFC, 2013.

IBIAPINA, M. L. Pesquisa Colaborativa: investigação formação e produção de conhecimentos. 1. ed. Brasília: Liber Livro, 2008.

MOREIRA, A. F.; CANDAU, V. M. Indagações sobre currículo: currículo, conhecimento e cultura. Brasília, 2008.

PACHECO, J. A. Escritos Curriculares. 1. ed. São Paulo: Cortez, 2005.

SILVA, T. T. Documentos de identidade: uma introdução às teorias do currículo. 1. ed. Belo Horizonte: Autentica, 1999.

SILVA, T. T. d. Teorias do currículo. Uma introdução crítica. 1. ed. Porto: Porto Editora, 2000.

VEIGA-NETO, A.; LARROSA, J.; GRÜN, M.; FISCHER, R. M. B.; SILVEIRA, R. M. H.; CORAZZA, S. M. Caminhos investigativos I: Novos 
olhares na pesquisa em educação. 1 . ed. Rio de

Janeiro: DP\&A, 2002.

VIGOTSKI, L. S. A formação Social da Mente. 1. ed.

São Paulo: Martins Fontes, 1994. 